Artigo

\title{
Análise de erros: um estudo com ingressantes de cursos de graduação
}

\author{
Mistakes analysis: a study with undergraduate students
}

\section{Análisis de errores: un estudio con estudiantes de pregrado}

\section{Resumo}

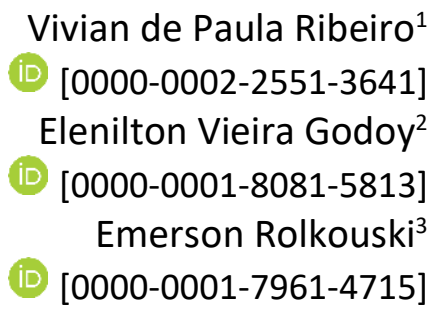

O presente artigo tem como objetivo identificar tipos de erros cometidos por estudantes ingressantes em cursos de graduação da Universidade Federal do Paraná na resolução de duas questões discursivas envolvendo funções quadráticas e compostas e suas correlações com aspectos atitudinais em relação à matemática. $\mathrm{O}$ artigo é o resultado de projetos de iniciação científica vinculados ao Programa Institucional de Bolsas de Iniciação Científica (PIBIC) da Universidade Federal do Paraná (UFPR) e desenvolvidos no período de setembro de 2018 a julho de 2019. Para tanto, duas questões discursivas sobre funções, constantes de uma avaliação diagnóstica, de caráter não obrigatória, aplicadas a 804 ingressantes dos cursos de - Administração, Agronomia, Ciências da Computação, Ciências Biológicas, Ciências Econômicas, Engenharias, Estatística, Física, Geologia, Informática Biomédica, Matemática, Matemática Industrial, Química e Zootecnia - foram analisadas, de acordo com os pressupostos da Análise de Conteúdo, e à luz de referenciais teóricos de análise de erros e da didática francesa. A análise das questões indicou sete categorias de erros: leitura do gráfico, conceito de função quadrática e propriedades, operações numéricas e simbologias, interpretação do problema, metodologia, transição da forma algébrica para geométrica, conceito de par ordenado. $O$ trabalho desenvolvido demonstrou que o uso da análise de erro pode ser uma poderosa ferramenta para auxiliar os estudantes na compreensão de regras matemáticas que, quando transferidas de um contexto para outro, sem o devido cuidado, invariavelmente, produzem resultados incorretos, além da necessidade da incorporação de situações que requeiram a mobilização de diferentes representações.

Palavras-chave: Educação Matemática no Ensino Superior. Análise de Erros. Função Quadrática. Função Composta.

\section{Abstract}

This article aims to identify kinds of mistakes made by incoming students from graduation courses from the Federal University of Paraná in solving two discursive questions involving quadratic and compound functions and their correlations with attitudinal aspects in relation to the mathematics. The

\footnotetext{
1 viviandpaularibeiro@gmail.com, Licenciada em Matemática, mestranda em Métodos Numéricos, Universidade Federal do Paraná, Curitiba/Paraná/Brasil.

2 elenilton@ufpr.br, Doutor em Educação, professor do Magistério Superior, Programa de Pós-Graduação em Educação em Ciências e em Matemática e Programa de Pós-Graduação em Educação - Universidade Federal do Paraná, Curitiba/Paraná/Brasil.

${ }^{3}$ rolkouski@uol.com.br, Doutor em Educação Matemática, professor do Magistério Superior, Programa de PósGraduação em Educação em Ciências e em Matemática - Universidade Federal do Paraná, Curitiba/Paraná/Brasil.
} 
article is the result of scientific initiation projects linked to the Scientific Initiation Scholarship Institutional Program (PIBIC) from the Federal University of Paraná (UFPR) and developed between September 2018 and July 2019. For that, two discursive questions about functions, included in a nonmandatory character diagnostic evaluation, applied to 804 incoming students from the courses Administration, Agronomy, Computer Sciences, Biological Sciences, Economic Sciences, Engineering, Statistics, Physics, Geology, Biomedical Informatics, Mathematics, Industrial Mathematics, Chemistry and Animal Science - were analyzed, according to the Content Analysis assumptions, and based on the error analysis theoretical references and the French didactics. The questions analysis indicated seven errors categories: the graphic reading, quadratic function and properties concept, numerical operations and symbologies, interpretation of the problem, methodology, transition from the algebraic to geometric form, ordered pair concept. The work developed showed that the error analysis usege can be a powerful tool to assist the students in understanding mathematical rules that, when transferred from a context to another, without due care, invariably produce incorrect results, in addition to the need of incorporation of situations that require the different representations mobilization.

Keywords: Mathematics Education in Higher Education. Mistakes Analysis. Quadratic function. Compound function.

\section{Resumen:}

El presente artículo tiene como objetivo identificar los tipos de errores cometidos por estudiantes que ingresan a cursos de graduación de la Universidade Federal de Paraná (UFPR) en la resolución de dos preguntas discursivas que envuelven funciones cuadrática y compuesta y sus correlaciones con aspectos actitudinales en relación a la matemática. Es el resultado de proyectos de iniciación científica, vinculados al Programa Institucional de Bolsas de Iniciação Científica (PIBIC) de la UFPR y llevados a cabo en el período de septiembre de 2018 a julio de 2019. De este modo, las dos preguntas discursivas sobre funciones, referentes a una evaluación diagnóstica y de carácter no obligatoria, fue aplicada a 804 ingresantes de los cursos de - Administración, Agronomía, Ciencias de la Computación, Ciencias Biológicas, Ciencias Económicas, Ingenierías, Estadística, Física, Geología, Informática biomédica, Matemática, Matemática Industrial, Química y Zootecnia; estas fueron analizadas, de acuerdo a los presupuestos del Análisis de Contenido y a la luz de referenciales teóricos del Análisis de Errores y de la Didáctica Francesa. El análisis de las preguntas indicó siete categorías de errores: lectura del gráfico, concepto de función cuadrática y propiedades, operaciones numéricas y simbología, interpretación del problema, metodología, transición de la forma algebraica a la geométrica y concepto de par ordenado. El trabajo desarrollado, indicó que el uso del Análisis de Errores puede ser una poderosa herramienta para auxiliar a los estudiantes en la comprensión de reglas matemática que, cuando son transferidas de un contexto para otro, sin el cuidado debido, invariablemente, producen resultados incorrectos, además de la necesidad de la incorporación de situaciones que requieran la movilización de diferentes representaciones.

Palabras clave: Educación Matemática en la Educación Superior. Análisis de errores. Función cuadrática. Función compuesta.

\section{Considerações iniciais}

Compreendemos que apenas constatar o quê estudantes erram em uma avaliação de conteúdos da matemática escolar pouco ou quase nada agrega ao trabalho docente tanto nas aulas de matemática da Educação Básica como nas aulas das disciplinas da área de matemática do Ensino Superior. Por outro lado, na medida em que, de modo sistemático, 
tomamos os erros como objeto de pesquisa, identificando não apenas o quê, ou o quanto os alunos erram, mas passando a considerar o porquê e como erram, podemos contribuir para o desenvolvimento de ações para que os alunos possam superá-los. Esse trabalho se insere nesse movimento.

O presente artigo tem como objetivo identificar tipos de erros cometidos por estudantes ingressantes em cursos de graduação da Universidade Federal do Paraná na resolução de duas questões discursivas envolvendo funções quadrática e composta e suas correlações com aspectos atitudinais em relação à matemática. Os resultados aqui apresentados são produto de projetos de iniciação científica, vinculados ao Programa Institucional de Bolsas de Iniciação Científica (PIBIC) da Universidade Federal do Paraná (UFPR) e desenvolvidos no período de setembro de 2018 a julho de 2019.

Os dados foram coletados na ocasião da aplicação de uma avaliação ${ }^{4}$ diagnóstica, realizada no primeiro semestre de 2018. Tal avaliação foi constituída de 24 questões, sendo vinte e duas (22) em formato de testes de múltipla escolha e duas (2) discursivas. As questões de 1 a 6 caracterizam o perfil educacional e atitudinal matemático dos participantes; a questão 7 objetivou apresentar o principal motivo que fez com que o ingressante escolhesse o curso em questão; as questões de 8 a 22, em formato de testes, avaliam o conhecimento matemático escolar da Educação Básica; e as questões 23 e 24, em formato discursivo, apareceram pela primeira vez neste ano (2018) e foram incluídas visando a esse projeto. A avaliação não é obrigatória e tampouco compõe o conceito final dos (as) estudantes nas disciplinas da área de Matemática.

A produção das alunas e alunos foram submetidas à análise qualitativa pautadas na análise de conteúdo (BARDIN, 2011), e discutidas à luz dos referenciais de Cury (2007, 2012), Cury, Bisognin e Bisognin (2009), Ribeiro e Cury (2015) e Almoloud (1997), dentre outros. Para cumprir o objetivo proposto, o presente artigo é assim estruturado: nessa introdução, apresentam-se as ideias gerais e a gênese da pesquisa, na sequência, o referencial teórico, a metodologia e as conclusões finais.

\section{Referencial teórico}

O presente referencial teórico tem como objetivo trazer discussões gerais sobre a tendência de pesquisa da Educação Matemática conhecida como Análise de Erros, e tem, como sua principal referência no Brasil a pesquisadora Helena Noronha Cury. Não obstante Cury, ser a principal referência, o tema "erros" é, naturalmente, objeto, senão de pesquisas, ao menos de reflexão para todos os educadores. Constitui-se, portanto, como uma metodologia de pesquisa e como metodologia de ensino.

Segundo Bigode (2007, p. 11) "o erro se constitui como um conhecimento", ou seja, se descartamos os erros cometidos, frequentemente, por falta de atenção ou descuido, então "os erros são hipóteses legítimas baseadas em concepções e crenças adquiridas ao longo da vida escolar". Ainda segundo Bigode (2007, p. 12)

\footnotetext{
${ }^{4}$ A avaliação diagnóstica é aplicada pelo departamento de Matemática desde 2016, nos diferentes cursos em que atua: Administração, Agronomia, Ciências da Computação, Ciências Biológicas, Ciências Econômicas, Engenharias, Estatística, Física, Geologia, Informática Biomédica, Matemática, Matemática Industrial, Química e Zootecnia.
} 
Hoje sabemos da importância de analisar essas respostas $\left(\frac{a}{b} \oplus \frac{c}{d}=\frac{a+c}{b+d}\right)$ [grifo nosso], indo além da remediação das mesmas, buscando suas causas e prevendo seus desdobramentos, aproveitando-as como objetos de conhecimento, investigando, com base na resposta, as concepções dos alunos a respeito de conceitos e procedimentos.

Somado ao erro $(5+6)^{2}=5^{2}+6^{2}$, o erro apresentado é um clássico que indica, não uma falta de atenção, ou descuido, mas uma transferência equivocada de algo que é verdadeiro num domínio, mas falso em outro. Tal compreensão, advinda de resultados de pesquisa, auxilia o professor a considerar outros encaminhamentos pedagógicos, que não somente, desconsiderar o que o aluno produziu solicitando a resolução mecânica de uma série de atividades repetitivas.

Concordamos com Cury (2007, p. 14) sobre o fato de que a análise das respostas dadas pelos estudantes a um problema permite ao professor e aos alunos, "a possibilidade de entender, mais de perto, como se dá a apropriação do saber dos estudantes".

A análise das respostas, além de ser uma metodologia de pesquisa, pode ser, também, enfocada como metodologia de ensino, se for empregada em sala de aula, como "trampolim para a aprendizagem" (BORASI $\left.{ }^{5}, 1985\right)$, partindo dos erros detectados e levando os alunos a questionar suas respostas, para construir o próprio conhecimento (CURY, 2007, p. 14).

Conforme Cury (2007, p. 14)

[...] a análise das produções dos estudantes não é um fato isolado na prática do professor; ela é - ou deveria ser - um dos componentes dos planos pedagógicos das instituições e dos planos de aula dos docentes, levando em conta os objetivos do ensino de cada disciplina.

A simples constatação de um erro cometido por um grupo de alunos em uma avaliação não auxilia, em nada, à aprendizagem do estudante. Mais do que constatar, o docente precisa investigar as causas destes erros e, se possível, ajudar a dirimi-los.

$O$ interesse pelo desenvolvimento do projeto surge da experiência de um dos autores deste artigo que, ao corrigir provas de Cálculo Diferencial e Integral, se deparava com erros do tipo, $\quad \lim _{n \rightarrow \infty} \frac{n^{2}+2 n}{n\left(1+\frac{3}{n}\right)}=\lim _{n \rightarrow \infty} \frac{n^{2}+2 n}{n(1)}=\infty, \quad \lim _{n \rightarrow \infty} \frac{n^{2}+2 n}{n+3}=\frac{n(n+2)}{n\left(1+\frac{3}{n}\right)}=\frac{n+2}{1+\frac{3}{n}}=\infty$, $\sqrt[n]{n^{2}+1}=\sqrt[n]{n^{2}}+\sqrt[n]{1} \ldots$ As perguntas que sempre ocorriam eram 'quais são os motivos que levam os estudantes a cometerem esses erros? Falta de atenção? Nervosismo no momento da prova? Pouca compreensão destes conceitos?...'

Segundo Cury (2012, p. 31), "para trabalhar com os erros e tomar decisões sobre eles, é preciso ter conhecimento do conteúdo envolvido e das fases de análise [...]". Para Cury (2012) isto indica que é preciso tomar decisões que são específicas dos docentes, uma vez que

\footnotetext{
${ }^{5}$ BORASI, R. Using errors as springboards for the learning of mathematics: an introduction. Focus on learning problems in mathematics, v. 7, n. 3-4, p. 1-14, 1985.
} 
"levam em conta, ao mesmo tempo, o que o aluno sabe, o que não sabe e o que pode ser feito para ajudá-lo a reorganizar seu pensamento sobre o conteúdo em questão" (Ibidem). Concordamos com Cury (2012, p. 33) sobre o fato de que "[...] não é possível hipotetizar sobre a origem de determinado erro se o professor [pesquisador] (grifo nosso) não domina aquele conteúdo".

\subsection{Análise de erros: uma ferramenta de aprendizagem}

Há autores que afirmam que o erro é um problema na aprendizagem e deve ser eliminado, visto como algo inaceitável, como é o caso de Brousseau ${ }^{6}$ (1983 apud Cury, 2009) que considera o erro não apenas ignorância, mas efeito da incerteza, acaso e de uma aprendizagem falha, referentes a erros que são baseados em um conhecimento prévio não adequadamente generalizado. Exemplo: a raiz quadrada de uma soma é a soma das raízes quadradas das parcelas $\sqrt{a+b}=\sqrt{a}+\sqrt{b}$ (conceito que seria verdadeiro em um contexto, porém falso em outro).

Em contrapartida, há também os que acreditam que o erro seja uma forma de encontrar as dificuldades dos alunos e ter a chance de trabalhar sobre elas, como no caso de Borasi $^{7}$ (1996 apud Cury, 2009) que sugere que os professores proponham atividades onde os alunos procurem exceções que funcionem com essa nova "regra", usando assim o erro como "um trampolim para a aprendizagem". Deve-se considerar também o processo e não apenas o produto. Krutetskii ${ }^{8}$ (1976 apud Cury, 2009) acreditava que resultados iguais poderiam ser frutos de processos mentais diferentes, que não necessariamente significaria habilidade. Logo, um acerto em um determinado problema não significaria o total domínio do conteúdo. Voltando para Borasi (1996 apud Cury, 2007), ela descreve o ato de errar como o ato de se perder em uma cidade, e é algo que parte da sua própria vontade de se posicionar em relação a isso. Para analisar melhor a reação de cada pessoa, ao decidir fazer algo a respeito, ela sugere três cenários diferentes e o papel do erro em cada um dos cenários:

Quadro 1 - Os diferentes cenários
\begin{tabular}{|c|l|l|l|}
\hline Cenário & Descrição & Consequência & O papel do Erro \\
\hline 01 & $\begin{array}{l}\text { Você precisa chegar ao } \\
\text { seu destino o mais rápido } \\
\text { possível }\end{array}$ & $\begin{array}{l}\text { Tem-se urgência em chegar ao seu destino, } \\
\text { provavelmente pedindo informações e/ou } \\
\text { seguindo mapas. }\end{array}$ & $\begin{array}{l}\text { Erro não é aceito, seu } \\
\text { único objetivo é o } \\
\text { resultado. }\end{array}$ \\
\hline 02 & $\begin{array}{l}\text { Um caminho que você } \\
\text { espera seguir muitas } \\
\text { vezes no futuro }\end{array}$ & $\begin{array}{l}\text { O ponto principal não é apenas chegar em } \\
\text { casa, e sim conhecer a cidade. }\end{array}$ & $\begin{array}{l}\text { Erro proporciona melhor } \\
\text { entendimento do tópico } \\
\text { em questão. }\end{array}$ \\
\hline $\begin{array}{l}\text { Você é um turista e se } \\
\text { perder pode ser uma } \\
\text { coisa bem-vinda }\end{array}$ & $\begin{array}{l}\text { O fato de ser um turista possibilita a a } \\
\text { exploração da cidade, onde caminhos } \\
\text { errados nos levam a conhecê-la ainda mais. }\end{array}$ & $\begin{array}{l}\text { Erro possibilidades de novos } \\
\text { aprendizados. }\end{array}$ \\
\hline
\end{tabular}

Fonte: Elaborada pelos autores (2019)

\footnotetext{
${ }^{6}$ BROUSSEAU, G. Les obstacles épistémologiques et les problémes en mathématiques. Recherches en didactique des mathématiques, n. 4.2 , p. 165-198, 1983.

7 BORASI, R. Reconceiving mathematics instruction: a focus on errors. Norwood, NJ: Ablex Publishing Corporation, 1996.
}

8 Krutetskii, V.A. The psychology of mathematical abilities in schoolchildren. Chicago: The University of Chicago Press, 1976. 
Ao fazer uma analogia, percebemos que o processo de aprendizagem leva tempo e determinação. Se, ao fazer um exercício, por exemplo, o aluno, como no primeiro cenário, se preocupar apenas com o resultado imediato, o aprendizado é falho. Nos dois cenários seguintes sugere-se que o erro não deve ser encarado como algo negativo, mas sim como uma ferramenta que leva o aluno a explorar novos horizontes. No segundo cenário percebe-se que o erro contribui não apenas para a conclusão do que era pedido antes, mas também para melhorar o entendimento do tópico estudado. O terceiro cenário sugere que o erro pode, inclusive, possibilitar novos aprendizados.

Ao separar em três cenários, o objetivo é fazer com que reflitamos a respeito do contexto em que o erro é cometido. Os estudantes veem o erro como uma falha acadêmica resultando em notas baixas, fazendo-os trabalhar sobre pressão, ficando frustrados com os erros cometidos e não procurando investir tempo para estudar seu próprio erro, por achar que é perda de tempo. No entanto o que deveria ser feito é exatamente o contrário, ou seja, ao perceber seu erro o aluno deveria explorá-lo, usando-o, segundo Cury (2007), como um 'trampolim para a aprendizagem'.

\subsection{O conhecimento pedagógico do conteúdo dos erros}

De acordo com Schulman ${ }^{9}$ (1986 apud Cury, 2012), três conhecimentos são indispensáveis ao professor: conhecimento do conteúdo, o conhecimento curricular e o conhecimento pedagógico do conteúdo. Ancorado nas ideias desse autor, Cury (2012) enfatiza a importância para o que denominou de conhecimento pedagógico do conteúdo dos erros.

O conhecimento pedagógico do conteúdo dos erros engloba a compreensão sobre as "pré-concepções" dos alunos, que muitas vezes são ideias equivocadas sobre um determinado assunto e as possibilidades pedagógicas que esse conhecimento possibilita para a reorganização de sua prática.

Para Cury (2012), o conhecimento pedagógico do conteúdo dos erros, exige muito mais do que o simples conhecimento do conteúdo ou da pedagogia. Segundo a autora,

[...] esse conhecimento deve incluir uma compreensão do que faz aquele determinado conteúdo fácil ou difícil; das concepções errôneas que os alunos têm sobre o conceito ou sobre suas operações e propriedades; das formas de auxiliar os alunos a desconstruir tais concepções (CURY, 2012, p. 37).

O conhecimento pedagógico do conteúdo dos erros envolve

[...] conhecer o conteúdo no qual o erro foi cometido, as razões pelas quais tal conteúdo gera erros, as formas de trabalhar com os erros para desestabilizar as concepções errôneas dos alunos e as estratégias de ensino que podem auxiliar os alunos a superar suas dificuldades de aprendizagem (CURY, 2012, p. 38).

A autora propõe do final de seu texto, que sejam abordados, em cada disciplina específica ou pedagógica de um curso de licenciatura em Matemática, os erros mais

\footnotetext{
${ }^{9}$ SHULMAN, Lee S. Those Who Understand: Knowledge Growth in Teaching. Educational Researcher. v.15, n.2. fev., p. 4-14, 1986.
} 
frequentes, cometidos por estudantes da Educação Básica, relacionados aos conceitos ensinados naquela disciplina.

Dessa forma, o futuro professor poderá ter, como sugere Shulman (1986), um arsenal de conhecimentos sobre as dificuldades, sendo que estas poderão ser discutidas em disciplinas de metodologia de ensino, de estágio, de psicologia educacional, ou quaisquer outras que envolvam o processo de ensino e aprendizagem. Portanto, ao trabalhar com erros, tanto em termos de conteúdos como de metodologias, o professor terá oportunidade de se preparar para planejar suas aulas, em qualquer abordagem escolhida, com os melhores exemplos, as melhores analogias, os melhores problemas sobre determinado conteúdo. Dessa forma, o professor estará desafiando concepções errôneas dos estudantes, previamente adquiridas, ou obstáculos gerados por novos conceitos, auxiliando-os na superação das dificuldades (CURY, 2012, p. 45).

Concordamos com as afirmações da autora, ressaltando a necessidade da incorporação, em cursos de formação inicial e continuada, da discussão de resultados de pesquisa sobre erros em todos os níveis de ensino e em todos os eixos da matemática escolar. Erros em geometria, por exemplo, possuem natureza diferente dos erros em álgebra ou em aritmética. Dado que a área escolhida para esse estudo é a álgebra, trataremos de tomá-la como tema na próxima seção.

\subsection{Dificuldades encontradas na aprendizagem de álgebra}

Ribeiro e Cury (2015) apresentam na obra "Álgebra para a formação do professor", ideias de pesquisadores que se preocupam em detectar as dificuldades dos estudantes, mais especificamente nos conteúdos de equações e funções, para criarem estratégias de ensino que venham auxiliá-los na aprendizagem dos conceitos em questão. Na mesma direção do que já discutimos na seção anterior, ressaltam que,

Ball, Thames e Phelps ${ }^{10}$ (2008) consideram essencial que o professor reconheça quando os alunos dão uma resposta errada ou quando os livrostexto utilizados apresentam alguma definição equivocada. Os autores apontam para a importância de buscar padrões nos erros dos alunos, para saber qual o melhor método para ensinar determinado tópico. Esses autores ainda sugerem, no seu esquema sobre os domínios do conhecimento para o ensino, o que chamam de conhecimento horizontal, que envolve saber o que já foi ensinado em um determinado nível de ensino e o que será ensinado depois, para poder ter a visão, por exemplo, da importância de discutir com os alunos aqueles erros recorrentes que tiveram origem em anos anteriores e que vão se consubstanciar em obstáculos para a aprendizagem de futuros conteúdos (RIBEIRO; CURY, 2015, p.83).

10 BALL, Deborah. L.; THAMES, Mark H.; PHELPS, Geoffrey. Content knowledge for teaching: what makes it special? In: Journal of Teacher Education. V. 59, n. 5, nov./dec, p. 389-407, 2008. 
Já, especificamente sobre dificuldades relacionadas à álgebra, relatam o uso incorreto da propriedade distributiva da multiplicação em relação à adição. Já, especificamente no trabalho com funções, afirmam que são comuns erros relacionados à linguagem.

Quanto ao primeiro erro Mariotti ${ }^{11}$ e Cerulli (2001 apud RIBEIRO; CURY, 2015, p. 76) mencionam que está presente a influência de um "esquema mental", ou seja, "imagem mental de um procedimento operatório que o aluno gravou sem ter compreendido perfeitamente". Com relação ao segundo, Ponte, Branco e Matos ${ }^{12}$ (2009 apud RIBEIRO; CURY, 2015) apontam que os estudantes podem entender quando se diz, por exemplo, que "a imagem de 5 é $3^{\prime \prime}$, mas não conseguem entender a expressão $f(5)=3$.

$\mathrm{Na}$ busca pelas causas de erros dessa natureza, os autores analisaram livros textos e resultados de pesquisas sobre o conhecimento do professor. Segundo Ribeiro e Cury (2015), os alunos possuem uma visão estreita sobre funções e uma das causas para isso seria a forma com que os livros-texto e professores apresentam esse tema. Além disso, há ausência de uma discussão mais profunda sobre o conceito de função em sala de aula, bem como a exploração das múltiplas representações das funções.

Para os autores, os livros-texto de Álgebra reforçam, em geral, procedimentos meramente operacionais (técnicas de resolução) e elementares, bem como:

[...] os aspectos transformacionais, com ênfase em regras a serem seguidas para a manipulação de expressões simbólicas, ao invés de atentar para as noções conceituais, que sustentam essas regras ou para o alicerce estrutural das expressões e equações (RIBEIRO; CURY, 2015, p.13).

Ribeiro e Cury (2015) apresentam algumas pesquisas em que são discutidos os conhecimentos dos professores relacionados ao conceito de função. Entre elas, a de Zuffi ${ }^{13}$ (1999 apud RIBEIRO; CURY, 2015), que:

[...] investigou a utilização da linguagem matemática por sete professores de Matemática do ensino médio. A autora conclui que, para esses professores, as regras e procedimentos estabelecidos pela comunidade escolar e pelos livros didáticos para o conceito de função têm mais destaque do que as definições formais que foram estudadas nos seus cursos de formação e que eles apresentam os formalismos da linguagem matemática apenas para cumprir com as exigências da escola ou dos vestibulares (RIBEIRO; CURY, 2015, p.20).

Dessa forma, o ensino de Álgebra é muitas vezes "ancorado na manipulação algébrica, sem o desenvolvimento das capacidades de abstração e generalização" (RIBEIRO; CURY, 2015, p. 16), essenciais para o pensamento algébrico. Segundo os autores, o pensamento algébrico inclui:

\footnotetext{
${ }^{11}$ MARIOTTI, M. A.; CERULLI, M. Semiotic Mediation for Algebra Teaching and Learning. In: Van den HeuvelPanhuizen, M. (Ed.). Proceedings of the 25th Conference of the International Group for the Psychology of Mathematics Education. Utrecht, NL, V. 3, p. 225-232, 2001.

12 PONTE, J. P. BRANCO, N. MATOS. A. Álgebra no ensino básico. 2009.

13 ZUFFI, E. M. O tema "funções" e a linguagem matemática de professores do Ensino Médio: por uma aprendizagem de significados. Tese (Doutorado em Educação). São Paulo: Faculdade de Educação, Universidade de São Paulo 1999.
} 
[...] a capacidade de lidar com expressões algébricas, equações, inequações, sistemas de equações e de inequações e funções. Inclui, igualmente, a capacidade de lidar com outras relações e estruturas matemáticas e usá-las na interpretação e resolução de problemas matemáticos ou de outros domínios (PONTE; BRANCO; MATOS, 2009 apud RIBEIRO; CURY, 2015, p. 13 e 14).

Outra ressalva é que o ensino dessa forma, proporciona ao estudante a impressão de que as funções e equações são um "amontoado de símbolos, regras e procedimentos, muitas vezes desprovidos de significado" (RIBEIRO; CURY, 2015, p. 20). Consequentemente, os alunos e as alunas podem encontrar dificuldades e até mesmo emoções negativas frente à matemática quando não se recordam de alguma fórmula ou algoritmo de resolução para tratar os problemas matemáticos. Por exemplo,

[...] o conhecimento da propriedade distributiva da multiplicação em relação à adição, se não entendida no ensino fundamental, pode trazer dificuldades no Cálculo Diferencial, quando o estudante precisa saber simplificar frações algébricas, entre outros itens. Também entendemos que uma concepção errônea do conceito de função pode levar o estudante a uma aprendizagem deficiente dos diversos tipos de função com que vai trabalhar no ensino médio ou superior (RIBEIRO; CURY, 2015, p. 83).

Tais afirmações vão ao encontro do observado por um dos autores desse artigo, conforme já relatado. De fato, a falta de compreensão de assuntos relacionados à álgebra escolar pode comprometer o desempenho em disciplinas como Cálculo Diferencial e Integral, Geometria Analítica, Álgebra Linear entre outras.

\section{Percurso metodológico}

O presente artigo teve como objetivo identificar tipos de erros cometidos por estudantes ingressantes em cursos de graduação da Universidade Federal do Paraná na resolução de duas questões discursivas envolvendo funções quadrática e composta e suas correlações com aspectos atitudinais em relação à matemática. 0 corpus de análise foram as respostas de 804 estudantes ingressantes a uma avaliação diagnóstica aplicada nos cursos de Administração, Agronomia, Ciências da Computação, Ciências Biológicas, Ciências Econômicas, Engenharias, Estatística, Física, Geologia, Informática Biomédica, Matemática, Matemática Industrial, Química e Zootecnia da Universidade Federal do Paraná.

\subsection{Sobre o instrumento de coleta de dados}

A avaliação diagnóstica possui caráter não obrigatório e não constitui parte da nota dos alunos em qualquer disciplina. Tal instrumento foi aplicado em 2018 e constituiu-se de 24 questões, a saber:

- Questões de 1 a 6: questões de múltipla escolha e visam a traçar o perfil educacional e atitudinal matemático dos estudantes;

- Questão 7: questão de múltipla escolha que solicita a motivação do aluno ter escolhido o referido curso; 
- Questões 8 a 22: questões de múltipla escolha que avaliam o conhecimento matemático escolar da Educação Básica;

- Questões 23 e 24: questões discursivas envolvendo os conteúdos de funções.

As questões 23 e 24 foram elaboradas exclusivamente para esse estudo, de acordo com pressupostos da engenharia didática (ARTIGUE, 1988), cujo processo de elaboração será descrito a seguir.

\subsubsection{A elaboração das questões (situação-problema)}

As questões 23 e 24 em formato discursivo, que constituíram a situação-problema, apareceram pela primeira vez no ano de 2018 e foram incluídas visando a esse projeto. As questões foram elaboradas e analisadas de acordo com pressupostos da engenharia didática de Michèle Artigue (1988).

A engenharia didática é uma forma de trabalho didático comparável ao trabalho de um engenheiro que, para realizar um projeto, se apoia nos conhecimentos científicos de seu domínio, aceita se submeter a um controle de tipo científico, mas, ao mesmo tempo, é obrigado a trabalhar objetos mais complexos que os objetos depurados da ciência, portanto de confrontar-se, com todos os meios que ele possui, aos problemas que a ciência não quer ou não pode ainda levar em conta (ARTIGUE, 1988 apud ALMOULOUD, 1997, p. 113)

Essas duas questões discursivas sobre o tema de ensino funções, relacionam o professor, os alunos e um elemento do saber matemático, objeto da aprendizagem (ALMOULOUD, 1997). As questões, foram assim enunciadas, aos ingressantes:

Figura 1 - Enunciados das questões discursivas analisadas

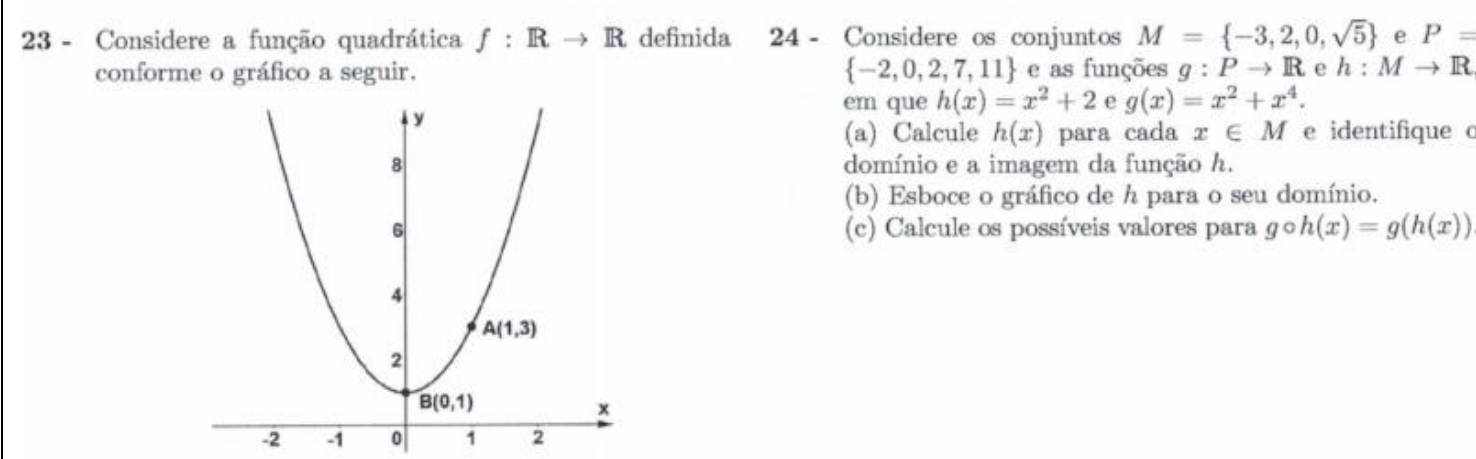

Encontre a lei de formação da função f.

Fonte: Elaborada pelos autores (2019)

As questões tinham como objetivo levar as alunas e alunos a relacionarem diferentes representações de uma função quadrática: gráfica e algébrica. Além disso, requeriam a compreensão dos elementos que a compõe - imagem e domínio - e requeriam conhecimentos de composição de funções.

$\mathrm{Na}$ questão 24, havia o diferencial de que o domínio e imagem eram conjuntos discretos de pontos e, portanto, o gráfico não é contínuo e sim um conjunto de pontos dispersos no plano cartesiano. Da mesma forma, para a composição de função, havia uma restrição no domínio que poderia apresentar uma dificuldade a mais para sua resolução. 
De acordo com Almouloud (1997), é interessante para a compreensão do conceito de função, mobilizarmos vários registros de representação, tais como: o gráfico, a escrita simbólica e linguística, pois cada um deles tem características próprias e podem ser importantes para os processos de ensino e de aprendizagem das funções, mais especificamente, da função quadrática, objeto da nossa investigação. Caso o aluno não esteja habituado a fazer a mudança da representação gráfica para o algébrico ou não entenda essas relações, ficará sujeito a permanecer com a concepção operacional muitas vezes elementar de função.

Já Silveira (2008) ressalta a importância de trabalhar diversos contextos em sala de aula para que o conceito seja compreendido. Para a autora (2008, p. 97), "compreender o conceito matemático é saber interpretar uma regra matemática em qualquer contexto. Pois desta forma, o processo de aplicação de regras não é mecânico, pois é necessária a interpretação".

Particularmente na questão 23 , demos ênfase à passagem da representação gráfica para algébrica, não por considerá-la mais importante, mas por verificarmos no estudo de Almouloud (1997), que este aspecto costuma ser pouco trabalhado nos materiais curriculares e em sala de aula. Dessa forma, as questões poderiam criar um obstáculo didático, já que se solicitava o caminho inverso, ou seja, a passagem do quadro geométrico para o algébrico.

Segundo Almouloud (1997), um possível obstáculo didático seria o tratamento das funções no registro de fórmulas durante toda a escolaridade, com a mudança do registro das fórmulas para o registro gráfico, mas sem a passagem inversa. Outro obstáculo seria o estudo gráfico de funções lineares ou afins unicamente no oitavo ou nono ano, constituindo um obstáculo didático suplementar à aquisição do conceito de função no primeiro ano do ensino médio.

\subsubsection{Análise matemática da situação-problema}

A situação-problema refere-se à resolução de questões discursivas envolvendo o conteúdo de funções. A questão 23 , requer que se encontre a lei de formação de uma função quadrática.

Possíveis soluções:

i) Interpretar que $f$ é uma função par por ser quadrática e então admitir o ponto $C=(-1,3)$ no seu gráfico. Diante disso, com três pontos encontramos a lei de formação $f(x)=2 x^{2}+1$, mediante um sistema com as três equações:

$a(1)^{2}+b(1)+c=3, a(-1)^{2}+b(-1)+c=3$ e $a(0)^{2}+b(0)+c=1$. Em que $a, b$ e $c$ são as incógnitas pertencentes ao conjunto dos números reais.

ii) Interpretar que o ponto $B$ é o vértice da função, com isso por intermédio do sistema composto pelas equações: $\frac{-b}{2 a}=0$ e $\frac{-b^{2}+4 a c}{4 a}=1$ encontrar a lei de formação $f(x)=a x^{2}+1$ e depois para encontrar o valor de a basta fazer $x=1 f(x)=3$ correspondente ao ponto $A=(1,3)$.

A questão 24 é composta pelos elementos de uma função, ou seja, domínio, imagem, representação geométrica e por composição de funções.

Solução do item a:

$O$ domínio da função $h$ é o conjunto $M=\{-3,2,0, \sqrt{5}\}$ e, portanto, o conjunto imagem é $\{2,6,7,11\}$ tal que $h(-3)=11 ; h(2)=6 ; h(0)=2 ; h(\sqrt{5})=7$ 
Solução do item b:

Figura 2 - Solução da questão 24, item b

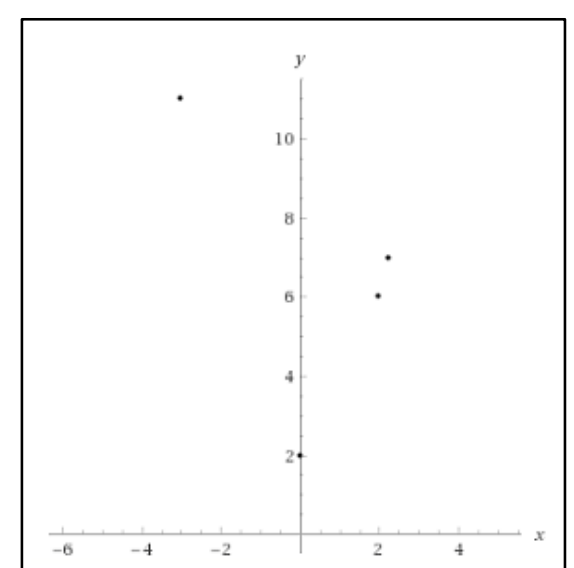

Fonte: Elaborado pelos autores (2019)
Possíveis soluções do item c:

Solução 1: O conjunto solução é $\left\{2^{2}+2^{4}, 7^{2}+7^{4}, 11^{2}+\right.$ $\left.11^{4}\right\}$ em que $g(h(-3))=11^{2}+11^{4} ; g(h(0))=2^{2}+2^{4}$; $g(h(\sqrt{5}))=7^{2}+7^{4}$

Solução 2:

Resolver $g o h(x)=g\left(x^{2}+2\right)=\left(x^{2}+2\right)^{2}+\left(x^{2}+2\right)^{4} e$ substituir os valores de $x \in M$ para os quais é possivel calcular $g\left(x^{2}+2\right)$, ou seja, o resultado de $x^{2}+2$ deve pertencer ao domínio de $g$.

\section{Os quadros colocados em jogo pela situação}

O quadro geométrico: gráficos e orientações no plano cartesiano serão fundamentais para resolução das questões 23 e 24 .

O quadro algébrico: equações, incógnitas, sistema de equações serão ferramentas para formular de uma outra maneira o problema.

O quadro numérico: números inteiros, racionais e irracionais, munidos da ordem e das operações, são ferramentas básicas para todas as etapas do estudo e para qualquer quadro onde se situe.

\section{As ferramentas}

Quanto aos conteúdos necessários para resolução dos problemas, podemos destacar: plano cartesiano e noções de pontos; características de uma função quadrática, parábola e lei de formação; domínio e imagem de funções; valor numérico de uma função; esboçar gráficos, bem como o conhecimento de suas características; determinar a composta de uma função; números e conjunto numérico; e operações matemáticas.

\section{As escolhas didáticas}

Levantamos as seguintes variáveis na situação-problema: quanto à representação, as funções do $2^{\circ}$ grau podem apresentar-se na forma algébrica ou gráfica; o conjunto numérico escolhido para trabalhar as situações foi o dos números reais e alguns subconjuntos reais; e a escolha dos pontos no gráfico que estavam presentes na função quadrática.

\section{Os procedimentos esperados que permitem avançar na resolução da situação-problema}

Nessa situação-problema (constituída pelas questões Q23 e Q24) é dada a representação gráfica da função quadrática, solicitando ao aluno que encontre primeiramente a lei de formação da função $f(Q 23)$.

Conforme mencionado, a passagem em que ocorre a mudança de quadros, do algébrico para o geométrico, é usualmente trabalhado nos materiais curriculares, razão pela qual escolhemos seguir o caminho contrário. Indica-se a necessidade de questões dessa natureza, para que os alunos adquiram maior flexibilidade na transição entre representações.

Ainda nessa perspectiva, escolhemos adentrar no conjunto dos números reais e algumas restrições de domínio, que muitas vezes não é considerado na Educação Básica. Além 
disso, embora presentes, situações em que se requer encontrar uma função quadrática são menos usuais que problemas equivalentes envolvendo funções afins (Q24A).

Depois desse processo, no item seguinte (Q24B) esperamos que o aluno se atente para a restrição que ocorreu no domínio e, portanto, o gráfico não será mais contínuo e sim um conjunto de pontos. Essa questão gera novamente um obstáculo para o aluno, uma vez que ele geralmente não aprende dessa forma, apenas the é ensinado a construir um gráfico contínuo.

No último item (Q24C) esperamos que o aluno lembre o conceito de função composta e verifique que só é possível a composição para valores de $f(x)$ que estão no domínio de $g(x)$. É possível que o aluno encontre dificuldades na interpretação do domínio das funções e no simbolismo matemático.

\section{Erros levantados numa análise a priori}

Da primeira questão discursiva (Q23), levantamos os seguintes erros:

- Leitura incorreta do gráfico

i) Visualizar que a parábola intercepta algum dos eixos no ponto $B$ e daí concluir que $f$ possui raiz dupla. Nessa situação, o aluno encontrará outra lei de formação ou cessará o processo antes de encontrar.

Solução: Se $f$ possui raiz dupla então $b^{2}-4 a c=0$. Dos pontos $A$ e $B$ temos $a(1)^{2}+b(1)+c=3$ e $a(0)^{2}+b(0)+c=1$. Resultando em uma lei de formação diferente de $f(x)=2 x^{2}+1$ ou processo interrompido em alguma etapa.

ii) Ao interpretar que $f$ possui raiz dupla, o aluno pode cometer o erro de pensar que $f(1)=$ 0 . Com isso, recorremos a possível solução:

Solução: $f(x)=(x-1)(a x+b)$ e substituindo essa função nos pontos $A$ e $C$ encontraremos uma lei de formação.

- Conhecimento equivocado sobre lei de formação, interpretando que é necessário encontrar uma tabela com os pontos do gráfico.

- Não lembrar que função quadrática é par e então não conseguir encontrar o terceiro ponto, simétrico ao ponto $A$. Com isso, o processo de resolução sucederá com apenas dois pontos ou então algum outro ponto da leitura do gráfico.

- Encontrar a lei de formação de uma função linear por só ter dois pontos.

- Trocar abscissa com ordenada dos pontos $A=(1,3), B=(0,1)$ e $C=(-1,3)$. E então o sistema formado por equações $f(x)=a x^{2}+b x+c$ estará incorreto.

- Trocar abscissa com ordenada em qualquer dos exemplos anteriores.

Da questão Q24, também discursiva, alguns erros se assemelham, mas ainda permanecem algumas idiossincrasias:

Q24A)

- Confundir o conceito de domínio e imagem. Encontrando assim conjuntos diferentes do esperado.

- Confundir imagem e contradomínio, obtendo como resposta que a imagem é o conjunto dos números reais. Essa confusão possibilitará erros como, por exemplo, $x^{2}+2=-3$.

- Calcular a imagem e no final responder que são os reais, por ver que os valores encontrados são reais. 
- Não conhecer o símbolo de pertence e, portanto, não entender que os valores de $x$ são aqueles que pertencem ao conjunto $M$.

Q24B)

- Escrever os números sem colocar em forma de conjunto.

- Não visualizar que o gráfico é um conjunto de pontos e acabar ligando todos eles.

- Ao interpretar na letra a) que o domínio de $h$ é o conjunto dos números reais ou algum outro diferente de $M$ resultará em um gráfico diferente do esperado.

Q24C)

O gráfico de $h$ ficará invertido se o aluno confundir abscissa e ordenada.

- Calcular $g(h(2))$ ao não observar que $h(2)$ não está no domínio de $g$.

- Pensar que o domínio de $g$ e $h$ é o conjunto dos números reais e encontrar somente alguns valores para a função composta.

- Não se atentar primeiramente ao domínio de $h(x)$ e depois para o domínio de $g(x)$. Encontrando resultados diferentes.

- Considerar $g_{o} h(x)=g(h(x))$ como uma equação e buscar a verificação dos pontos em $g_{o} h(x)=g\left(x^{2}+2\right)=(x+2)^{2}+\left(x^{2}+2\right)^{4}$. Para os valores de $x$ o aluno pode cometer o erro de utilizar qualquer número real, todos os números do conjunto $M$ ou $P$. Ou então utilizar o conjunto $M$ união/interseção com $P$.

- Considerar $g o h(x)$ como o produto entre $g$ e $h(x)$. Possibilitando as seguintes soluções:

Solução 1) $\operatorname{goh}(x)=\left(x^{2}+x^{4}\right) \cdot\left(x^{2}+2\right)$ e escolher valores de $x$ pertencentes ao conjunto $P$ ou qualquer outro.

Solução 2) De $g o h(x)=g(h(x))$ implica que $\left(x^{2}+x^{4}\right) \cdot\left(x^{2}+2\right)=(x+2)^{2}+\left(x^{2}+2\right)^{4}$. Diante disso escolher valores de $x$ da mesma maneira da solução 1 . $O$ aluno pode tentar resolver essa equação ou apenas fazer a verificação da igualdade.

Solução 3) De $g . h(x)$ fazer $g . h(x)=\left(x^{2}+x^{4}\right) . h(x)$ substituindo valores para $x$ somente na lei de formação da função $h$ :

$g o h(x)=\left(x^{2}+x^{4}\right) \cdot h(-3)=11\left(x^{2}+x^{4}\right)$

$\operatorname{goh}(x)=\left(x^{2}+x^{4}\right) \cdot h(2)=6\left(x^{2}+x^{4}\right)$

$\operatorname{goh}(x)=\left(x^{2}+x^{4}\right) \cdot h(0)=2\left(x^{2}+x^{4}\right)$

$\operatorname{goh}(x)=\left(x^{2}+x^{4}\right) \cdot h(\sqrt{5})=7\left(x^{2}+x^{4}\right)$

Diante disso, o aluno pode apenas colocar todas as opções de $g . h(x)$ ou então substituir outros valores em $x$.

Nesse capítulo, destacamos aspectos relacionados aos procedimentos metodológicos, e, em particular à elaboração da situação-problema de acordo com os pressupostos da engenharia didática. No próximo capítulo, apresentaremos a análise dos dados.

\section{A análise dos dados}

A análise dos dados foi realizada a partir das conceituações feitas por Laurence Bardin sobre a análise de conteúdo, tal como foram adaptadas por Cury $(2007,2009)$. Ao usar a metodologia da análise de conteúdo proposta por Bardin ${ }^{14}$ (1979), "as respostas escritas de estudantes a questões de Matemática podem ser objeto de uma análise aprofundada e sistemática." (CURY, 2009, p. 2).

\footnotetext{
${ }^{14}$ Bardin, L. Análise de conteúdo. Lisboa: Edições 70, 1979.
} 
Bardin assinala a pré-análise, a exploração do material e o tratamento dos resultados como sendo as etapas básicas para o trabalho de análise de conteúdo. Cury adapta o método para analisar os erros cometidos pelos estudantes:

[...] primeiramente fazemos uma leitura "flutuante" de todo o material, para avaliar as respostas. A seguir, as separamos em "totalmente corretas", "parcialmente corretas" e "incorretas", fazendo a contagem do número de respostas de cada tipo. [...] Nessa primeira fase, já empregamos algum tipo de notação para separar aquelas respostas sobre as quais nos debruçaremos, o corpus da pesquisa. Em um próximo passo, aprofundamos a análise, realizando a unitarização e categorização das respostas. Nesse momento, 0 pesquisador já produz uma interpretação dos dados, pois estabelece os critérios segundo os quais cria as categorias. [...] Já na fase de tratamento dos resultados, as categorias são apresentadas por meio de quadro com indicação de frequências e percentagens ou com a produção de um "textosíntese" que resuma cada uma, incluindo-se, também, exemplos dos erros cometidos. A partir dessa compreensão mais aprofundada, pode-se utilizar os resultados da investigação com fins teóricos ou práticos (CURY, 2007, p. $3)$.

Tais etapas, foram por nós seguidas. Na primeira fase de análise, as respostas a cada questão da avaliação diagnóstica foram separadas ('em branco' e 'respondidas') e organizadas, formando o corpus sobre o qual realizamos o trabalho. As provas 'em branco' foram arquivadas e as 'respondidas' foram corrigidas. Na correção das soluções de cada uma das questões discursivas, consideramos quatro categorias:

- E: Errado $\rightarrow$ errou algum processo da resolução e, portanto, entrará para análise.

- B: Branco $\rightarrow$ deixou em branco a questão.

- A: Acertou $\rightarrow$ conseguiu resolver de forma correta e coerente todos os passos.

- I: Inconclusivo $\rightarrow$ respostas sem o desenvolvimento ou desenvolvidas corretamente até um determinado ponto, mas não concluídas. Deixando a questão com dados insuficientes para análise.

Da leitura das produções consideradas erradas, emergiram as seguintes categorias: R1. Leitura do gráfico; R2. Conceito de função quadrática e propriedades; R3. Operações numéricas e simbologias; R4. Interpretação do problema; R5. Metodologia; R6. Transição da forma algébrica para geométrica; e R7. Conceito de par ordenado.

$\mathrm{Na}$ etapa seguinte do nosso trabalho, organizou-se um quadro com os cursos, erros nas questões discursivas, número de acertos nas questões objetivas e as perguntas da avaliação diagnóstica referente ao perfil do estudante: gênero, quantidade de aulas semanais de matemática, tipo de escola (pública, particular ou mista), relação com a matemática (ama, gosta, indiferente, não gosta ou tem pavor).

Embora não seja o objetivo desse artigo analisar as respostas das questões objetivas, ressaltamos que, nessas questões, foi realizado um teste estatístico multivariado, objetivando estabelecer comparações entre a variável dependente (o número de acertos das questões objetivas) e as demais variáveis independentes envolvidas (gênero, aulas semanais de matemática, tipo de escola, conhecimento sobre disciplina de matemática no curso, relação com a matemática e motivo da escolha do curso). 
Nessa análise constatou-se que a escola particular produz um acerto médio 2,09 maior do que a pública e 1,2 maior do que a mista (alunos que cursaram parte do ensino médio em escola pública e parte em escola particular). Não há diferença significativa entre a média dos acertos de estudantes provenientes de escolas mistas (parte em pública, parte em privada) e escolas públicas.

Amar matemática produz um acerto médio de 1,15 superior a gostar; 2,3 superior a indiferente; 2,397 superior a não gostar; e 3,44 superior a ter pavor. Gostar de matemática produz um acerto médio 1,16 superior a indiferente. $O$ efeito tanto do tipo de escola como de gostar de matemática foram, portanto, significativos. As demais variáveis não influenciaram sobre o número de acertos.

Portanto, a principal variável do processo diz respeito a quanto o estudante gosta ou tem repulsa pela disciplina. Isto ressalta a importância de se preservar uma atitude positiva do estudante frente à matemática. O outro ponto importante é a qualidade do processo escolar, associando a escola particular, e, possivelmente às condições socioeconômicas da família, a um melhor desempenho acadêmico em matemática.

A análise que optamos por apresentar neste artigo tomará com referência os sentimentos dos alunos e alunas em relação à matemática e os tipos de erros apresentados nas duas questões discursivas (Q23 e Q24), conforme explicitado nos quadros 2, 3 e 4. Para a variável 'relação com a matemática' criamos três categorias. O sentimento positivo (amar ou gostar da matemática); o sentimento nulo (indiferente à matemática); e o sentimento negativo (não gostar ou ter pavor da matemática).

\section{Análise da Questão 23}

Com relação à questão 23, temos o seguinte quadro:

Quadro 2 - Sentimento x Desempenho na Questão 23

\begin{tabular}{|c|c|c|c|c|c|c|c|c|c|c|c|c|}
\hline \multirow{2}{*}{ Sentimento } & \multicolumn{12}{|c|}{ Questão 23} \\
\hline & Acertou & Branco & R1 & $\mathrm{R} 2$ & R3 & R4 & R5 & R6 & R7 & Inconclusivo & Total & Erros \\
\hline Positivo & 159 & 150 & 11 & 115 & 31 & 5 & 12 & 0 & 0 & 180 & 663 & 174 \\
\hline Nulo & 13 & 34 & 0 & 25 & 2 & 2 & 0 & 0 & 0 & 29 & 105 & 29 \\
\hline Negativo & 1 & 12 & 0 & 8 & 1 & 0 & 0 & 0 & 0 & 14 & 36 & 9 \\
\hline Total & 173 & 196 & 11 & 148 & 34 & 7 & 12 & 0 & 0 & 223 & 804 & 212 \\
\hline
\end{tabular}

Fonte: Elaborada pelos autores (2019)

A partir das informações apresentadas no quadro 2 temos que o principal erro cometido na questão 23, independentemente do sentimento em relação à matemática foi o R2 (Conceito de função quadrática e propriedades). Os principais erros identificados e associados ao 'Conceito de função quadrática e propriedades' foram:

- Não lembrou que função quadrática é par e então não conseguiu encontrar o terceiro ponto, simétrico ao ponto $A$. Com isso, o processo de resolução sucedeu com apenas dois pontos ou então algum outro ponto da leitura incorreta do gráfico.

- Encontrou a lei de formação de uma função linear por só ter dois pontos.

- Calculou o determinante com os dois pontos, encontrando uma reta.

- Trocou o sinal do coeficiente do $x^{2}$ por achar que a concavidade é voltada para baixo ou achar que a concavidade voltada para cima apresenta sinal negativo. 
- Resolveu o sistema com os dois pontos, chegando em $a+b=2$. Daí concluir que $a=b=1$ ou $a=2$ e $b=0$. Obtendo assim duas leis de formação. Não conseguiu interpretar que cada função tem somente uma lei de formação.

- Considerou que numa função quadrática o coeficiente de $x^{2}$ é sempre 1 . E, portanto, considerar apenas duas incógnitas para o problema.

- Errou a forma genérica de uma função quadrática. Por exemplo: $a x^{2}+b y+c=0$.

- Igualou a lei de formação a 0 , encontrando uma equação como resposta.

- Encontrou uma lei de formação para cada um dos pontos A e B.

\section{Análise da Questão 24}

Com relação à questão 24 , item a, temos o seguinte quadro:

Quadro 3 - Sentimento x Desempenho na Questão 24A

\begin{tabular}{|c|c|c|c|c|c|c|c|c|c|c|c|c|}
\hline \multirow{2}{*}{ Sentimento } & \multicolumn{10}{|c|}{ Questão 24A } \\
\cline { 2 - 16 } & Acertou & Branco & R1 & R2 & R3 & R4 & R5 & R6 & R7 & Inconclusivo & Total & Erros \\
\hline Positivo & 160 & 23 & 0 & 111 & 94 & 128 & 0 & 0 & 0 & 147 & 663 & 333 \\
\hline Nulo & 19 & 9 & 0 & 14 & 14 & 23 & 0 & 0 & 0 & 26 & 105 & 51 \\
\hline Negativo & 3 & 3 & 0 & 5 & 7 & 6 & 0 & 0 & 0 & 12 & 36 & 18 \\
\hline Total & 182 & 35 & 0 & 130 & 115 & 157 & 0 & 0 & 0 & 185 & 804 & 402 \\
\hline
\end{tabular}

Fonte: Elaborado pelos autores (2019)

A partir das informações apresentadas no quadro 3 temos, diferentemente do que constatado no quadro 2, três erros com percentuais muito próximos, quais sejam o R2 (Conceito de função quadrática e propriedades), o R3 (Operações numéricas e simbologias) e o R4 (Interpretação do problema). Os principais erros identificados e associados ao 'Conceito de função quadrática e propriedades' na questão 24A foram:

- Confundiu o conceito de domínio e imagem. Encontrando assim conjuntos diferentes do esperado.

- Confundiu imagem e contradomínio, concluindo que a imagem é o conjunto dos números reais. Essa confusão gerou o erro $x^{2}+2=-3$.

- Definiu o domínio e imagem da função $h(x)$ sem levar em consideração a restrição dada no enunciado.

- Considerou o conceito de domínio como sendo $x$ e isolou x na regra como solução.

- Confundiu os conceitos de domínio e imagem e trocou seus valores. Exemplo: $D(f)=\{2,6,7,11\}$ $\operatorname{lm}(f)=\{-3,0,2,5\}$

- Utilizou o conjunto P para calcular $\mathrm{h}(\mathrm{x})$.

Os principais erros identificados e associados às 'Operações numéricas e simbologias' na questão $24 \mathrm{~A}$ foram:

- Não atribui significado correto ao símbolo de pertence e, portanto, não considerou que os valores de $x$ são aqueles que pertencem ao conjunto $M$.

- Notação incorreta de conjunto para as respostas ou a resposta em forma de intervalo.

- Utilizou apenas uma parte da regra da função, encontrando um conjunto imagem diferente do esperado.

- Errou no processo de operações numéricas.

- Utilizou a lei de formação de g para calcular o domínio e imagem de h.

Os principais erros identificados e associados à 'Interpretação do problema' na questão 24A foram: 
- Calculou a imagem e no final responder que são os reais, reais positivos, inteiros ou naturais, por ver que os valores encontrados pertencem a um desses conjuntos. Não interpretou corretamente quais valores pertencem ao domínio.

- Não interpretou que o domínio é o conjunto $M$ e no final respondeu que são os reais, reais positivos ou qualquer outro conjunto.

- Não se atentou para a restrição do domínio e respondeu que o domínio é igual ao conjunto imagem.

Com relação à questão 24 , item $b$, temos o seguinte quadro:

Quadro 4 - Sentimento x Desempenho na Questão 24B

\begin{tabular}{|c|c|c|c|c|c|c|c|c|c|c|c|c|}
\hline \multirow{2}{*}{ Sentimento } & \multicolumn{12}{|c|}{ Questão 24B } \\
\hline & Acertou & Branco & $\mathrm{R} 1$ & $\mathrm{R} 2$ & R3 & R4 & R5 & R6 & R7 & Inconclusivo & Total & Erros \\
\hline Positivo & 34 & 72 & 0 & 27 & 3 & 122 & 0 & 379 & 20 & 6 & 663 & 551 \\
\hline Nulo & 2 & 12 & 0 & 5 & 2 & 15 & 0 & 65 & 1 & 3 & 105 & 88 \\
\hline Negativo & 0 & 6 & 0 & 2 & 0 & 6 & 0 & 21 & 0 & 1 & 36 & 29 \\
\hline Total & 36 & 90 & 0 & 34 & 5 & 143 & 0 & 465 & 21 & 10 & 804 & 668 \\
\hline
\end{tabular}

Fonte: Elaborado pelos autores (2019)

A partir das informações apresentadas no quadro 4 temos que os dois principais erros cometidos na questão $24 \mathrm{~B}$, independentemente do sentimento em relação à matemática, foram o R4 (Interpretação do problema) e o R6 (Transição da representação algébrica para a gráfica). Os principais erros identificados e associados à 'Interpretação do problema' foram:

- Esboçou apenas o eixo das abscissas.

- Tentou esboçar ou esboçou o gráfico de h ou g de acordo com a lei de formação, sem identificar os pontos esperados.

- Construiu um esboço simples e por isso encontrou um gráfico com dados insuficientes.

O principal erro identificado e associado à 'Transição da representação algébrica para a gráfica' foi - não perceber que o gráfico é formado por um conjunto discreto de pontos e acabar ligando todos os pontos de alguma forma.

Com relação à questão 24 , item c, temos o seguinte quadro:

Quadro 5 - Sentimento x Desempenho na Questão 24C

\begin{tabular}{|c|c|c|c|c|c|c|c|c|c|c|c|c|}
\hline \multirow{2}{*}{ Sentimento } & \multicolumn{12}{|c|}{ Questão 24C } \\
\hline & Acertou & Branco & R1 & $\mathrm{R} 2$ & R3 & R4 & R5 & R6 & R7 & Inconclusivo & Total & Erros \\
\hline Positivo & 24 & 190 & 0 & 132 & 83 & 172 & 0 & 0 & 0 & 62 & 663 & 387 \\
\hline Nulo & 0 & 48 & 0 & 10 & 8 & 31 & 0 & 0 & 0 & 8 & 105 & 49 \\
\hline Negativo & 0 & 23 & 0 & 1 & 2 & 7 & 0 & 0 & 0 & 3 & 36 & 10 \\
\hline Total & 24 & 261 & 0 & 143 & 93 & 210 & 0 & 0 & 0 & 73 & 804 & 446 \\
\hline
\end{tabular}

Fonte: Elaborada pelos autores (2019)

A partir das informações apresentadas no quadro 5 temos que os três principais erros cometidos na questão $24 \mathrm{C}$, independentemente do sentimento em relação à matemática, foram o R2 (Conceito de função quadrática e propriedades), o R3 (Operações numéricas e simbologias) e o R4 (Interpretação do problema). Os principais erros identificados e associados ao 'Conceito de função quadrática e propriedades' foram:

- Não observou que h (2) não pertence ao domínio de g e por isso calculou g(h(2)). 
- Não se atentou primeiramente ao domínio de $\mathrm{h}(\mathrm{x})$ e depois para o domínio de $\mathrm{g}(\mathrm{x})$. Encontrando resultados diferentes.

- Não interpretou corretamente o domínio ou confundiu imagem com contradomínio da função composta e por isso encontrou valores incorretos.

- Conceito errado de função composta, identificando somente valores correspondentes à $\mathrm{g}(\mathrm{x})$

- Considerou que a função composta representa a soma de duas funções.

- Considerou que a função composta representa o produto de duas funções

O principal erro identificado e associado à 'Operações numéricas e simbologias' na questão $24 C$ foi desenvolver de maneira incorreta alguma operação matemática durante o processo.

Os principais erros identificados e associados à 'Interpretação do problema' na questão 24C foram:

- Interpretou que tanto o domínio de g como o de h é o conjunto dos números reais (ou qualquer outro) e encontrou somente alguns valores para a função composta.

- Interpretou incorretamente (possíveis valores) e buscou os valores de x que satisfaziam uma equação ou inequação.

- Não calculou todos os possíveis valores, só alguns.

- Encontrou $g(h(x))=(x+2)^{2}+\left(x^{2}+2\right)^{4}$, desenvolveu a expressão e não encontrou os valores.

- Interpretou incorretamente e calculou $h(g(x))$.

- Interpretou que o domínio da função composta é a intersecção ou união do domínio de g e $\mathrm{h}$ e por isso encontrou valores incorretos.

\section{Erros identificados com maior frequência}

Tendo em vista a grande ocorrência dos erros abaixo, decidimos por evidenciá-los em seção à parte.

O erro que ocorreu com maior frequência na questão 23, foi "encontrar a lei de formação de uma função linear, uma vez que o problema só destaca dois pontos no gráfico", conforme se pode observar na figura 3:

Figura 3 - Erro com maior frequência na questão 23

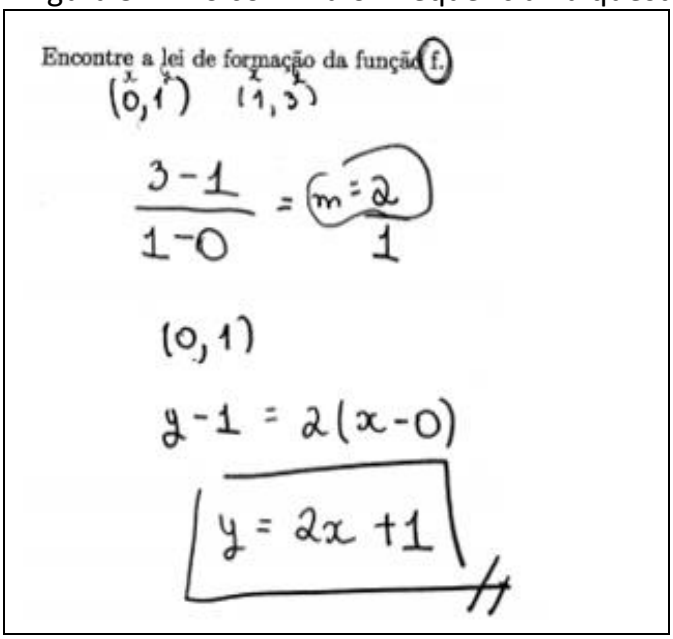

Fonte: Elaborada pelos autores (2019)

Já na questão 24, item a, o erro "resolver corretamente a primeira parte da questão 24A. Entretanto, no final responder que o domínio são os reais, reais positivos ou qualquer outro conjunto", foi o de maior frequência. O erro é exemplificado na figura 4: 
Figura 4 - Erro com maior frequência na questão 24, item a

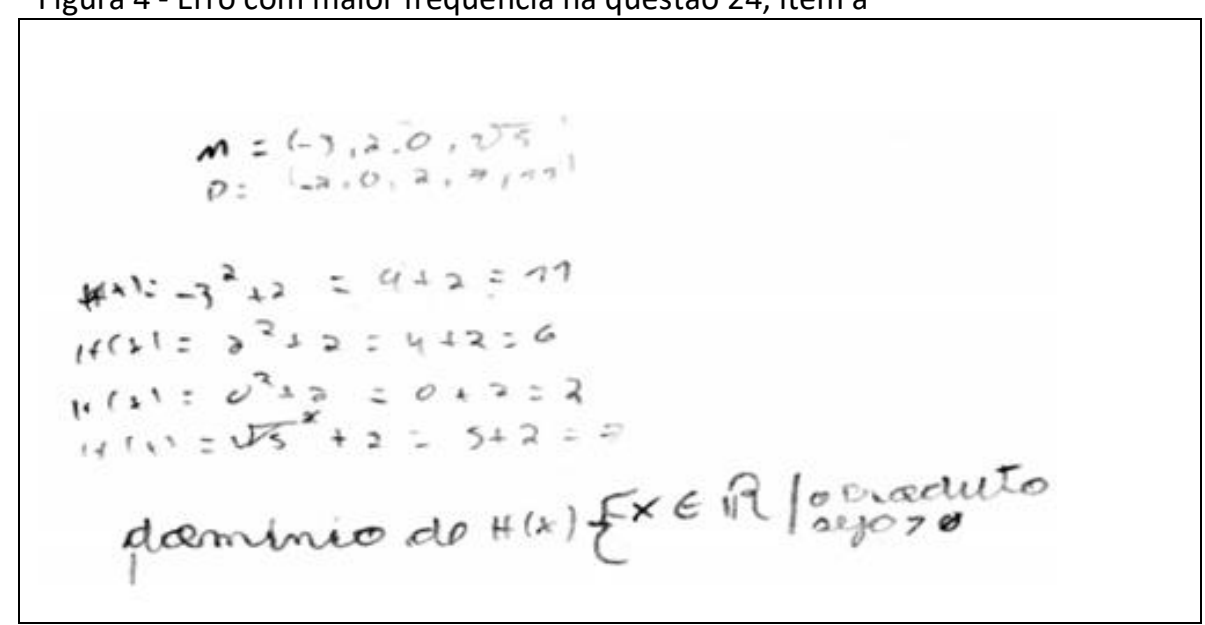

Fonte: Elaborada pelos autores (2019)

No item b da questão 24, o erro "não visualizar que o gráfico é um conjunto de pontos dispersos no plano cartesiano e ligar todos os pontos de alguma forma", foi o erro mais frequente. Tal erro é ilustrado na figura 5:

Figura 5 - Erro com maior frequência na questão 24, item b

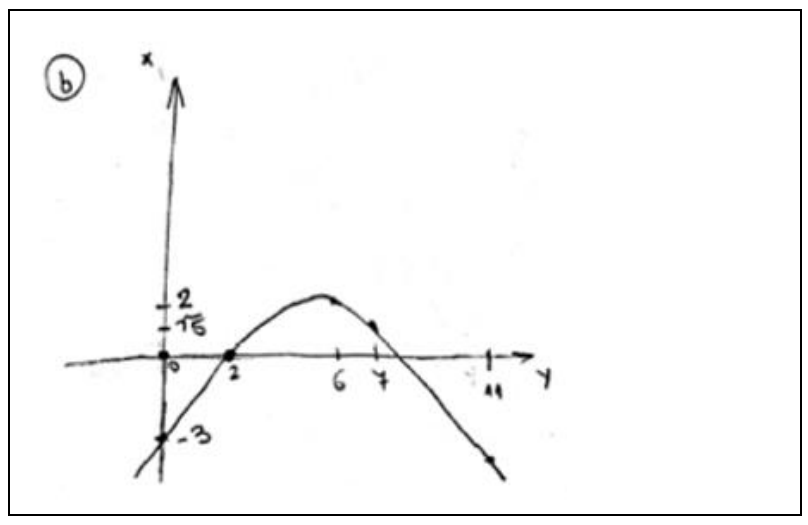

Fonte: Elaborada pelos autores (2019)

Finalmente, o erro mais frequente no item c da questão 24, foi "encontrarg $(h(x))=$ $(x+2)^{2}+\left(x^{2}+2\right)^{4}$ desenvolvê-la e não encontrar os valores esperados". Observa-se que esse erro foi decorrente da interpretação equivocada de $g_{o} h(x)=g(h(x))$. A figura 6, ilustra o erro:

Figura 6 - Erro com maior frequência na questão 24, item c

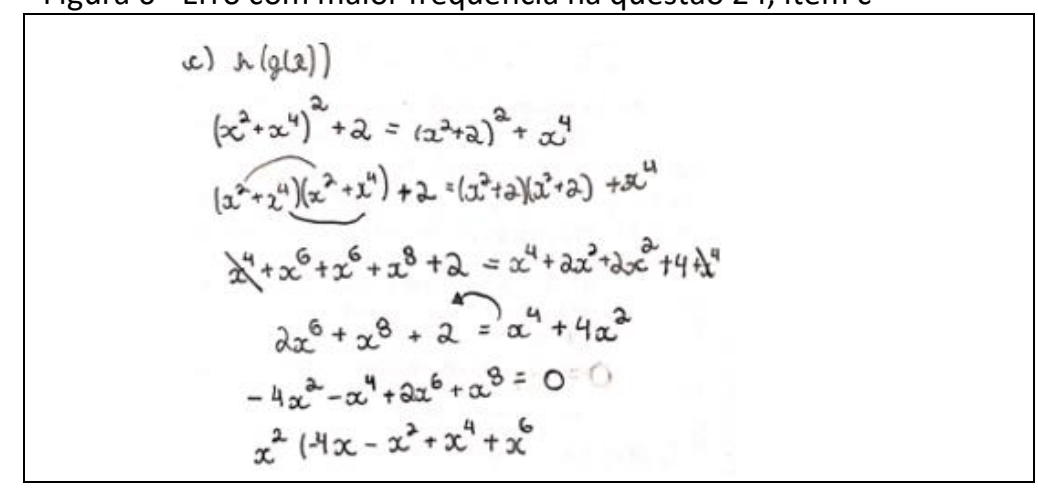

Fonte: Elaborada pelos autores (2019) 
Conforme previsto na análise a priori inspirada nas etapas da engenharia didática e nos demais autores, os alunos utilizaram estratégias basicamente procedimentais, mecânicas e técnicas. Apresentando dificuldades na caracterização do conceito de função e os seus elementos (domínio e imagem). Tal fato é corroborado por Silveira (2008, p. 105), quando afirma que

[...] muitas vezes algumas regras matemáticas são tão obscuras para o aluno e em sua concepção tudo parece tão vago e sem sentido, que ele também pode produzir regras que não tenham sentido. [...] Esse fato acontece porque ele não consegue ler e compreender o que está além da regra, assim, transforma a regra e cria outra em seu lugar.

Verificamos a limitação do conceito de função nas resoluções, bem como com os termos que fazem parte da própria definição de função. Constatamos também a dificuldade em explorar as múltiplas representações das funções. A mudança de contexto gerou um obstáculo para os estudantes e consequentemente muitos erros. Tais resultados corroboram com as ideias dos autores supracitados sobre a importância de explorar diferentes contextos e representações para a compreensão do conceito.

\section{Considerações finais}

O presente artigo teve como objetivo identificar tipos de erros cometidos por estudantes ingressantes em cursos de graduação da Universidade Federal do Paraná na resolução de duas questões discursivas envolvendo funções quadrática e composta e suas correlações com aspectos atitudinais em relação à matemática. O corpus de análise derivou da aplicação de uma avaliação diagnóstica aos estudantes ingressantes de cursos de graduação da Universidade Federal do Paraná, que possuem disciplinas de matemática em sua grade curricular.

O desenvolvimento e os resultados do trabalho, mostrou-nos que o uso da análise de erro pode ser uma poderosa ferramenta para auxiliar os estudantes na compreensão de certas regras matemáticas que, quando transferidas de um contexto para outro, sem o devido cuidado, invariavelmente, produzem resultados incorretos. Outro ponto importante diz respeito ao fato de que os diferentes registros de representação, bem como as mudanças de quadros devem ser privilegiados, igualmente, no estudo das funções, objetivando melhor compreensão do conceito e tipos de funções.

Compreendemos ser necessário que o olhar do professor esteja dirigido às manifestações dos alunos no processo de aplicação de certas regras matemáticas, para obter uma melhor compreensão de alguns importantes obstáculos na construção dos conceitos, bem como estar ciente de que existem outras variáveis que podem influenciar no desempenho, como a relação do aluno para com a matemática. Para a autora Chacón (2003), a ansiedade, o medo, o temor, o desespero - e não a perplexidade, a confusão, o quebrar a cabeça ou o bloqueio e a frustração, de acordo com a autora são estados afetivos essencialmente indesejáveis. Ademais, "formam uma estrutura estável que impede a resolução satisfatória do problema” (2003, p. 142). Eles, ocasionalmente, podem aparecer, mas é fundamental que os estudantes aprendam respostas para essas emoções negativas. 
Os livros didáticos e professores destacam a matemática como "amontoado de símbolos, regras e procedimentos, muitas vezes desprovidos de significado" (RIBEIRO; CURY, 2015, p.20), com isso os alunos não se apropriam dos conceitos e da construção do pensamento matemático. Como principal resultado, encontram muitas dificuldades na universidade, onde muitas vezes será preciso utilizar esses conceitos para os assuntos de maior complexidade. Esperamos que a leitura desse artigo auxilie todos aqueles que se preocupam com o ensino e aprendizagem da matemática à alteração desse quadro.

\section{Referências}

ALMOULOUD, Saddo. Ag. Fundamentos da didática da Matemática e metodologia de pesquisa. PUC-SP: Pontifícia Universidade Católica de São Paulo, 1997.

ARTIGUE, Michèle. Ingèniere didactique. RDM, v. 9, n. 3, p. 231-308, 1988.

BARDIN, Laurence. Análise de Conteúdo. Tradução de Luís Antero Reto e Augusto Pinheiro. São Paulo: Edições 70, 2011.

BIGODE, Antonio. J. Prefácio. In: CURY, Helena N. Análise de erros: o que podemos aprender com as respostas dos alunos. Belo Horizonte: Autêntica, 2007.

BORASI, Raffaella. Reconceiving mathematics instruction: a focus on errors. Norwood, NJ: Ablex, 1996.

CHACÓN, Inés M. G. Matemática Emocional: os afetos na Aprendizagem Matemática. Tradução: Daisy Vaz de Moraes. Porto Alegre, RS: Artmed, 2003.

CURY, Helena N.; BISOGNIN, Eleni; BISOGNIN, Vanilde. A análise de erros como metodologia de investigação. (2009). Disponível em:

www.apm.pt/files/142359_CO_Cury_Bisognin_Bisognin_4a36c5d50a09a.pdf. Acessado em 02. Fev. 2019.

CURY, Helena N. Análise de erros: o que podemos aprender com as respostas dos alunos. Belo Horizonte: Autêntica, 2007.

CURY, Helena N. O conhecimento pedagógico do conteúdo dos erros. In: VIANNA, Carlos R. (org.) Formação do Professor de Matemática: reflexões e propostas. Santa Cruz do Sul, RS: Editora IPR, 2012.

RIBEIRO, Alessandro J.; CURY, Helena N. Álgebra para a formação do professor. Belo Horizonte: Autêntica Editora. (Coleção Tendências em Educação Matemática), 2015.

SILVEIRA, Maria. R. A. Aplicação e interpretação de regras matemáticas. Educação Matemática Pesquisa, São Paulo, v.10, n.1 p. 93-113, 2008. 